\title{
Resíduos de frutos de pequi no controle do nematóide das galhas em tomateiro
}

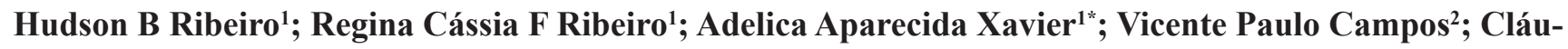 \\ dia Regina Dias-Arieira ${ }^{3}$; Edson Hiydu Mizobutsi ${ }^{1^{*}}$ \\ 'UNIMONTES-Depto. Ciências Agrárias, C. Postal 91, 39440-000 Janaúba-MG; hudson.brito@yahoo.com.br; regina.ribeiro@ \\ unimontes.br; adelica@unimontes.br; ${ }^{2}$ UFLA-Depto. Fitopatologia, 37200-000 Lavras-MG; vpcampos@ufla.br; ${ }^{3}$ UEM, Estrada da Paca \\ s/n, 87507-190 São Cristovão-PR; cdiasarieira@brturbo.com.br
}

\section{RESUMO}

Durante a extração do mesocarpo interno do pequi que corresponde à parte comestível e possui valor comercial, são descartados no ambiente o exocarpo e o mesocarpo externo. Objetivou-se neste trabalho investigar o uso do extrato aquoso e do pó moído dos resíduos de pequi no controle do nematóide das galhas (Meloidogyne javanica). Do exocarpo e do mesocarpo externo foram obtidos extrato aquoso e o pó moído. Cinco doses do extrato aquoso $(0,0 ; 2,5 ; 5$; 10 ou $20 \%$ ) foram avaliadas quanto ao efeito na eclosão e mortalidade de juvenis de segundo estádio (J2) do nematóide das galhas in vitro. Os ensaios foram montados em delineamento inteiramente casualizado com 10 repetições por tratamento. $\mathrm{O}$ teste de eclosão foi feito em câmaras de eclosão às quais foram adicionados 800 ovos do nematoide e $10 \mathrm{~mL}$ das diferentes doses do extrato. Durante 14 dias contou-se o número de $\mathrm{J} 2$ eclodidos com auxílio do microscópio ótico. O ensaio de mortalidade de $\mathrm{J} 2$ do nematóide das galhas foi avaliado colocando-se $100 \mu \mathrm{L}$ de cada dose do extrato em cada célula da placa Elisa e $20 \mu \mathrm{L}$ contendo $20 \mathrm{~J} 2$. Após 24 h contou-se o número de nematoides vivos e mortos. O pó de pequi moído foi testado em tomateiro em casa de vegetação em quatro doses $(0 ; 7,5$; 15 ou $30 \mathrm{~g} / 4 \mathrm{~kg}$ de solo) em delineamento em blocos ao acaso com 10 repetições por tratamento. $\mathrm{O}$ pó de pequi foi incorporado sete dias antes do plantio do tomateiro e a inoculação de ovos do nematoide foi feita após o plantio. Após 40 dias foram avaliados: o número de galhas, massas de ovos, ovos por raiz e $J 2 / 200 \mathrm{~cm}^{3}$ de solo e altura e peso de massa seca de parte aérea do tomateiro. $\mathrm{O}$ extrato aquoso reduziu significativamente a eclosão e aumentou a mortalidade de J2 do nematóide das galhas. O aumento das doses do pó reduziu o número de galhas, massas de ovos e ovos do nematóide das galhas por sistema radicular, bem como o peso da massa seca de parte aérea e da altura do tomateiro os quais são indicativos de fitotoxicidade.

Palavras-chave: Meloidogyne javanica, Caryocar brasiliense, composto orgânico.

\author{
ABSTRACT \\ Pequi fruit waste in the control of root-knot nematodes in \\ tomato
}

The exocarp and external mesocarp of pequi fruit are discarded during the extraction of internal mesocarp which is the commercial part used as food. The objective of this research was to study the use of aqueous extract and of pequi ground-powder to the control of root-knot nematode (Meloidogyne javanica). From ground pequi fruit exocarp and external mesocarp were obtained the aquaeous extract and powder. Five doses of aquaeous extract $(0.0 ; 2.5 ; 5 ; 10$ or $20 \%$ ) were evaluated on root-knot nematode J2 (second stage juvenile) hatching and mortality. The assays were carried out in entirely randomized design with 10 replications. The hatching assay was set in Petri plates with 800 nematode eggs and $10 \mathrm{~mL}$ of different doses of extract. During 14 days we counted the number of hatched juveniles under optical microscope. The mortality assay of root-knot nematode was evaluated putting $100 \mu \mathrm{L}$ of each dose of extract plus $20 \mu \mathrm{L}$ of supension containing $20 \mathrm{~J} 2$ in each cell Elisa plate. After $24 \mathrm{~h}$ was counted the number of live and dead juveniles. The pequi powder was tested in tomato plants in greenhouse in four doses $(0$; $7.5 ; 15$ or $30 \mathrm{~g} / 4 \mathrm{~kg}$ of soil) in randomized blocks design with 10 replications per treatment. The pequi powder was incorporated to the soil seven days before transplanting and nematode eggs inoculation was carried out after transplanting. After 40 days we evaluated the number of galls, egg masses, eggs/root and $J 2$ per $200 \mathrm{~cm}^{3}$ soil and the tomato shoot dry weight and height. The aquaeous extract reduced $\mathrm{J} 2$ hatching and increased J2 mortality. The increased application of powder doses reduced the number of galls, egg masses and eggs of root-knot nematodes per root system and the tomato shoot dry weight being a good indication of phytotoxicity.

Keywords: Meloidogyne javanica, Caryocar brasiliense, root-knot nematode, organic amendment.

(Recebido para publicação em 2 de maio de 2011; aceito em 20 de junho de 2012)

(Received on May 2, 2011; accepted on June 20, 2012)

$\mathrm{O}^{\mathrm{p}}$ pequizeiro (Caryocar brasiliense), é cultivado em todo o cerrado brasileiro. Dentre os estados produtores, Minas Gerais se destaca como o principal produtor e consumidor de pequi (Ribeiro, 2000). Além do valor alimentício, esta planta tem sido utilizada para fins medicinais, produção de mel, em ornamentação, produção de óleo e ta- nino (Vieira \& Martins, 2000; Marques et al., 2002). Durante o período da safra no Norte de Minas Gerais que vai de novembro a fevereiro, o pequizeiro é uma importante fonte de geração de renda para o agricultor local. Isto ocorre em função do envolvimento de toda família na catação dos frutos e na venda nas cidades circunvizinhas. No entanto, no processo de comercialização do fruto de pequi desprezam-se o exocarpo (casca) e a polpa externa (mesocarpo externo) que constituem $32,77 \%$ de resíduo (Perez, 2004).

Muitos resíduos agrícolas, a exemplo da manipueira e de mamona têm sido considerados agentes poluidores ou tóxicos às plantas (Zuchi et al, 
2007; Santos, 2009). Entretanto, o emprego de tais resíduos em campo, em doses adequadas e após a compostagem, pode constituir-se em tática de controle de fitonematoides e melhoria da fertilidade do solo. Nesse sentido o uso de produtos de origem vegetal, incluindo tortas de resíduos vegetais, adubos verdes, estercos de animais e pó de materiais vegetais de diferentes espécies de plantas vem sendo estudado como medida alternativa no manejo de fitonematoides e no desenvolvimento de plantas por promoverem a adição de nutrientes e melhoria da estrutura do solo (Oyedumade \& Olabiyi 2005; Pegoraro et al., 2005; Jesse et al., 2006; Olabiyi et al., 2007; Lopes et al., 2008; Ramos et al., 2009; Nazareno et al., 2010). Na decomposição desses produtos vegetais podem ser produzidos ácidos orgânicos, sulfeto de hidrogênio, fenóis, taninos e compostos nitrogenados, os quais são tóxicos aos nematoides das galhas (Mian \& Rodriguez-Kabana, 1982).

A ocorrência de princípios ativos (Perez, 2004) nos resíduos de pequi que também ocorrem em outras plantas e são tóxicos a nematoides poderá viabilizar o uso desses resíduos no controle de espécies de Meloidogyne ssp., além de constituir-se numa atividade econômica, social e ecologicamente interessante, uma vez que possibilitará a geração de novos empregos e redução do lixo no meio ambiente.

Princípios ativos no controle de fitopatógenos e zoonoses têm sido investigados em diversos órgãos do pequizeiro. Extratos metanólicos e etanólicos de folhas, botões florais, frutos (mesocarpo externo, mesocarpo interno e amêndoa) têm efeito fungitóxico na germinação de esporos de Botrytis cinerea, Colletotrichum truncatum e Fusarium oxysporum (Marques et al., 2002). Extratos de folhas têm atividade moluscicida contra Biomphalaria glabrata, hospedeiro intermediário da esquistossomose (Bezerra et al., 2002). No entanto, ainda não se investigou a eficácia de resíduos do pequi no controle de fitonematoides.

Assim este trabalho teve por objetivo avaliar a eficiência do extrato de pequi na eclosão e mortalidade de juvenis do nematóide das galhas in vitro, bem como o efeito de diferentes doses do pó moído de resíduos de pequi no controle do nematóide das galhas em tomateiro (Lycopersicon esculentum) em casa de vegetação.

\section{MATERIAL E MÉTODOS}

Os ensaios foram realizados na Universidade Estadual de Montes Claros, campus Janaúba. Foram selecionados frutos de pequi para o consumo sem nenhuma injúria externa. Esses frutos foram lavados e cortados para a obtenção do epicarpo (casca) e mesocarpo externo (polpa), picados e levados à estufa a $65^{\circ} \mathrm{C}$ por 72 horas. Em seguida, o material foi triturado em moinho elétrico Tecnal TE em peneira de 0,6 mm (30 mesh) e utilizado no ensaio em casa de vegetação. Para a obtenção do extrato, pesaram-se $200 \mathrm{~g}$ do material triturado e adicionaram-se 1 L de água destilada fria. A suspensão foi mantida em repouso por 48 horas em erlenmeyers envolvidos em papel alumínio à temperatura ambiente. Em seguida, a suspensão foi filtrada em papel Whatman $n^{\circ} 1$. Foram realizadas diluições em água destilada a fim de se obter as doses de 2,5, 5, 10 ou $20 \%$. A suspensão foi armazenada em geladeira por 3 dias até a realização dos testes in vitro. Para isto, ovos do nematóide das galhas, caracterizados por meio de corte perineal (Hartman \& Sasser, 1985), foram obtidos a partir de galhas de raízes de tomateiros do grupo Santa Cruz cv. Kada, mantidos em casa de vegetação em solo previamente tratado com brometo de metila na proporção de $150 \mathrm{~cm}^{3} / \mathrm{m}^{3}$ de solo. Para a extração dos ovos, as raízes foram lavadas e picadas em pedaços de aproximadamente $1 \mathrm{~cm}$ e em seguida transferidas para o liquidificador com solução de hipoclorito de sódio $0,5 \%$. Foram trituradas por 20 segundos na menor velocidade. A suspensão obtida foi vertida na peneira de $0,85 \mathrm{~mm}$ (20 mesh) sobre a de 0,25 $\mathrm{mm}$ (60 mesh) mm e de $0,025 \mathrm{~mm}$ (500 mesh). Os ovos retidos na peneira de 0,025 $\mathrm{mm}$ foram coletados em becker (Hussey \& Barker, 1973 modificada por Boneti \& Ferraz 1981) constituindo-se no inóculo para os testes in vitro e em casa de vegetação. Em seguida foram quantificados em câmaras de Peters e a suspensão calibrada para 800 ovos/ $\mathrm{mL}$ para os experimentos in vitro e para 2000 ovos/mL para o experimento em casa de vegetação. Os juvenis de segundo estádio (J2) foram obtidos a partir de câmara de eclosão feita em funil de Baermann. Os J2 obtidos após 24 h foram descartados e coletados aqueles produzidos após 48 h. A suspensão de J2 foi calibrada em câmara de Peters para $1000 \mathrm{~J} 2 / \mathrm{mL}$.

Efeito do extrato aquoso da casca e polpa externa de pequi na eclosão e mortalidade de juvenis de segundo estádio de do nematóide das galhas in vitro - O teste de inibição de eclosão foi feito em câmaras de eclosão montadas em placas de Petri de nove centímetros de diâmetro. No fundo da placa colocou-se uma peneira e sobre ela três folhas de papel absorvente. Sobre o papel foi adicionado $1 \mathrm{~mL}$ de suspensão contendo 800 ovos do nematóide das galhas. A seguir adicionaram-se sob o conjunto, peneira+ papel absorvente, $10 \mathrm{~mL}$ do extrato de pequi diluído em água por placa. As placas foram levadas à incubadora à temperatura de $25^{\circ} \mathrm{C}$ no escuro. Foram estudadas cinco doses do extrato $(0,0$; 2,$5 ; 5 ; 10$ ou $20 \%$ ) em delineamento inteiramente casualizado, com 10 repetições/tratamento. Cada placa foi considerada uma repetição. $\mathrm{O}$ ensaio foi avaliado contando-se o número de J2 eclodidos a cada 48 h durante 14 dias com auxílio do microscópio. Para isto, todo o volume do extrato de pequi na placa era retirado juntamente com os J2 eclodidos e reposta à mesma quantidade do extrato de pequi.

$\mathrm{O}$ efeito na mortalidade dos $\mathrm{J} 2$ de $M$. javanica das doses do extrato foi avaliado colocando-se $100 \mu \mathrm{L}$ de cada dose em cada célula da placa Elisa (capacidade de $300 \mu \mathrm{L} /$ célula) e $20 \mu \mathrm{L}$ da suspensão de J2 (concentração de $20 \mathrm{~J} 2 / 20 \mu \mathrm{L}$ ). Vinte e quatro horas após adicionou-se a cada célula da placa Elisa uma a duas gotas de $\mathrm{NaOH} 1 \mathrm{~N}$ e imediatamente fez-se a contagem dos nematoides com o corpo reto e imóveis, caracterizados como mortos, e os nematoides apresentando o corpo retorcido como vivos (Chen \& Dickson, 2000).

A porcentagem de eclosão dos $\mathrm{J} 2$ referente à contagem dos sete dias foi expressa pela área abaixo da curva de 
progresso de eclosão (AACPE), calculada pela equação de Shaner \& Finney (1997). Os dados obtidos foram transformados em $\sqrt{(\mathrm{x}+0,5)}$ para a realização da análise de variância e procedeu-se à análise de confiança entre as médias, associada ao teste $\mathrm{T}$ a $5 \%$ de probabilidade visto que não houve ajuste de modelos lineares. Para o teste de mortalidade, os dados foram convertidos em porcentagem, submetidos à análise de variância e ajustados ao modelo de regressão linear.

Avaliação do pó de casca e de polpa externa do pequi, em pó, no controle do nematóide das galhas em tomateiro - O pó obtido da casca e polpa externa do pequi foi colocado em quatro quilos de solo esterilizado em vasos e misturados (capacidade de $5 \mathrm{~L}$ ). Sete dias após transplantou-se uma muda de tomateiro "Kada" grupo Santa Cruz com 20 dias de idade. Em seguida fez-se a inoculação com suspensão contendo 2.000 ovos do nematóide das galhas em três orifícios abertos ao redor da muda. As plantas foram diariamente irrigadas e receberam os tratos culturais recomendados para a cultura. Foram testadas cinco doses do pó obtido da casca e polpa externa de pequi: $0 ; 7,5$; 15 e $30 \mathrm{~g} /$ por $4 \mathrm{~kg}$ de solo. $\mathrm{O}$ ensaio foi instalado em blocos ao acaso com 10 repetições. A parcela experimental foi constituída por um vaso contendo uma planta de tomate.

Quarenta dias após o transplantio das mudas avaliou-se a altura e a massa seca da parte aérea das plantas. Para isso, as partes aéreas foram cortadas ao nível do solo e secas em estufa a $65^{\circ} \mathrm{C}$ por 72 horas.

Em seguida, as raízes das plantas foram coletadas, lavadas e submetidas à coloração com floxina B (Taylor \& Sasser, 1978). Avaliaram-se, então, o número de massas de ovos expostas e galhas por sistema radicular. A seguir, as raízes foram cortadas em pedaços de $5 \mathrm{~mm}$ e trituradas para obtenção dos ovos (Hussey \& Barker, 1973 modificada por Boneti \& Ferraz, 1981). Além disso, avaliou-se o número de juvenis de segundo estádio (J2)/200 $\mathrm{cm}^{3}$ de solo ao final do experimento, de acordo com a técnica de Jenkins (1964). Os resultados do número de massas de ovos foram submetidos à análise de variância e procedeu-se à análise de confiança entre as médias, associada ao teste $\mathrm{T}$ a $5 \%$ de probabilidade visto que não houve ajuste de modelos lineares de regressão. Para as demais variáveis ajustou-se o modelo linear de regressão.

\section{RESULTADOS E DISCUSSÃO}

Pela análise da AACPE, todas as doses do extrato da casca e do mesocarpo externo do fruto de pequi pré-estabelecidas neste estudo reduziram a eclosão de juvenis de J2 do nematóide das galhas, quando comparadas com o controle, apenas água. Porém as doses de 10 e $20 \%$ reduziram a eclosão em 87,71 e $99,9 \%$, respectivamente, comparadas com o controle (água) e foram mais eficazes que as demais (Figura 1A). A mortalidade de J2 do nematóide

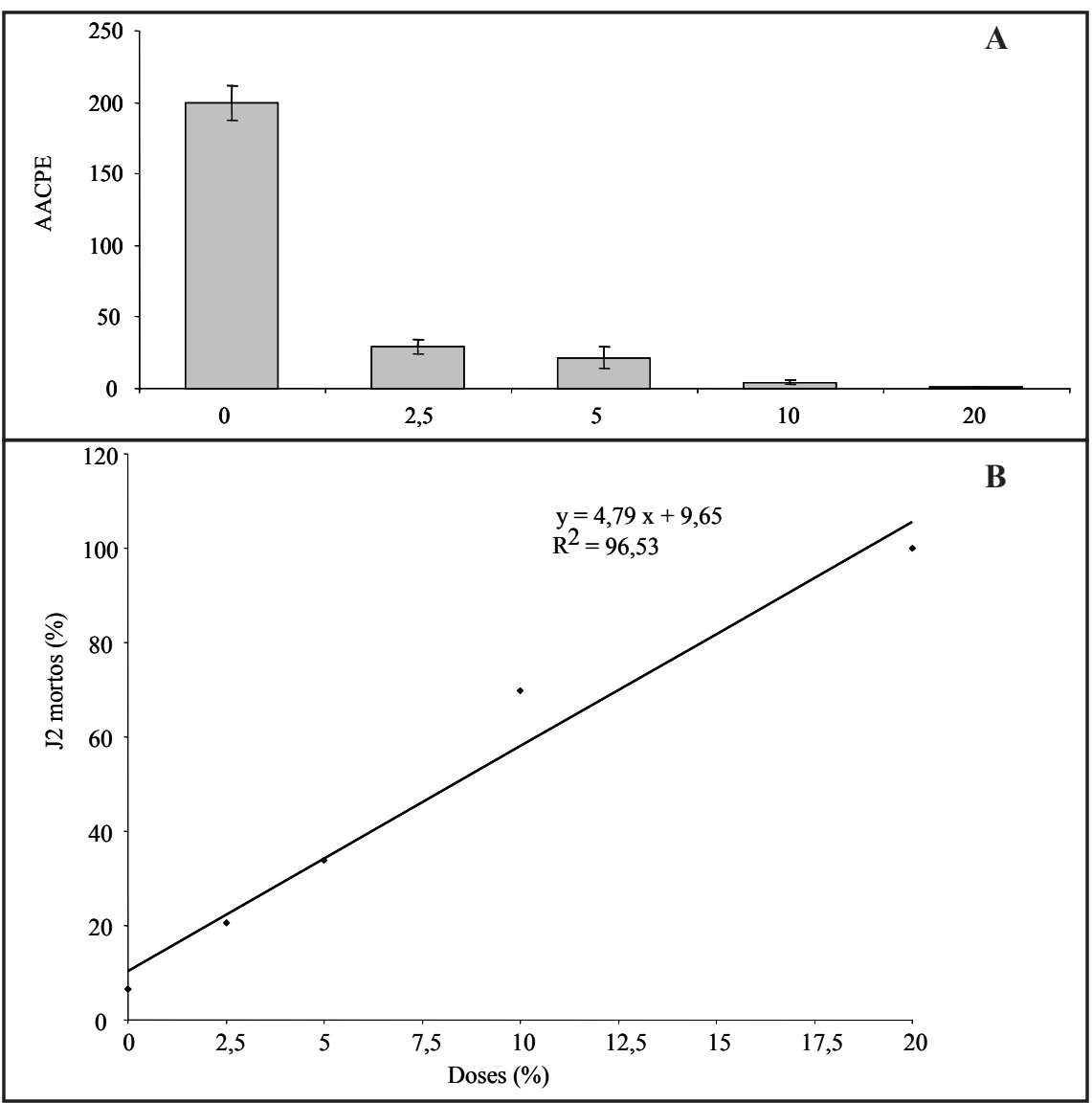

Figura 1. Área abaixo da curva de progresso de eclosão (AACPE) de juvenis de segundo estádio (J2). As barras representam o intervalo de confiança, associado ao teste T a $5 \%$ de probabilidade (A) e porcentagem de $\mathrm{J} 2$ dos nematóides das galhas mortos (B) em diferentes doses de extrato aquoso da casca e mesocarpo externo do pequi [area under the progress curve of juvenile hatching (AUCHP). The bars represent the confidence interval associated to T-test at $5 \%$ probability $(\mathrm{A})$ and of percentage juvenile mortality $(\mathrm{B})$ in relation to different doses of aquaeous extract of pequi powder (B)]. Janaúba, UNIMONTES, 2006. 


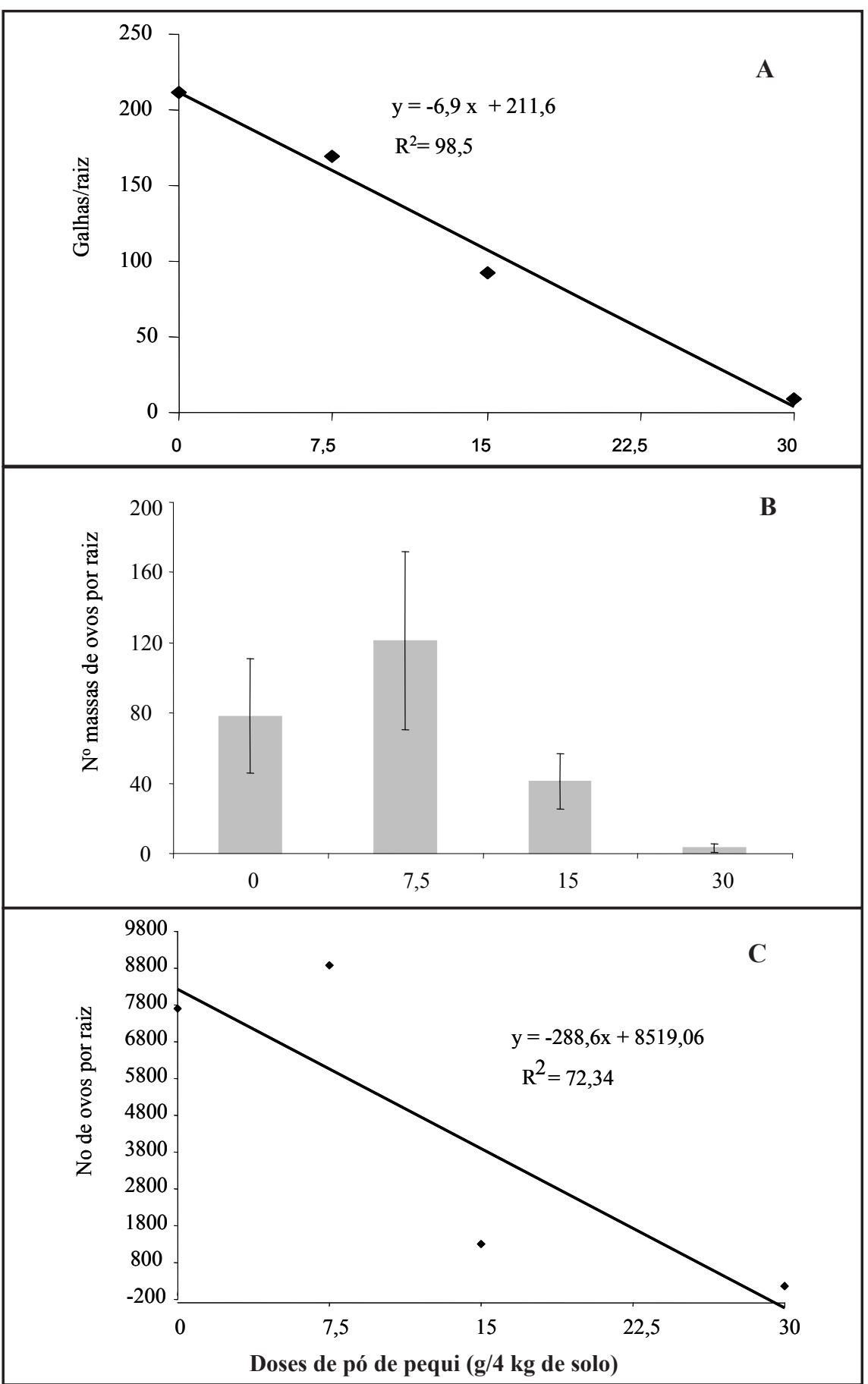

Figura 2. Número de galhas (A), massas de ovos (B), e ovos (C) por raiz de tomateiros inoculados com nematóides das galhas, quarenta e sete dias após a incorporação ao substrato de diferentes doses de pó da casca e mesocarpo do pequi. As barras representam o intervalo de confiança, associado ao teste $\mathrm{T}$ a $5 \%$ de probabilidade [number of galls (A), egg masses (B) and eggs (C) per tomato root system inoculated with root knot nematode, forty-seven days after the incorporation to the substrate of different doses of pequi powder. The bars represent the confidence interval associated to T- test at 5\% probability]. Janaúba, UNIMONTES, 2006.

(1991) relaciona a capacidade deste fitoquímico de reagir com membranas modificando a sua integridade e inibindo a fosforilação oxidativa. Extratos de folhas de erva-de-santa luzia (Euphobia hirta), quebra-pedra (Phyllanthus amarus), sene (Cassia obtusifolia), malva-baixa (Sida acuta) e capimandropogon (Andropogon gayanus) causaram $100 \%$ de mortalidade de $\mathrm{J} 2$ de $M$. incognita e também têm em suas composições taninos, saponinas, flavonóides, alcalóides e esteróides (Olabiyi et al., 2008). Folhas de cravode-defunto africano (Tagetes erecta), raízes de mentrasto-do-grande (Hyptis suaveolens) e alfavacão (Ocimum gratissimum) possuem saponinas e flavonóides nos extratos de raízes que reduzem a população de $M$. incognita em tomateiro (Olabiyi, 2004). Além disso, tem se constatado que extratos de outras plantas têm demonstrado efeito tóxico a fitonematoides (Costa et al., 2003; Salgado \& Campos, 2003; Adegbite \& Adesiyan, 2005).

O número de galhas e o número de ovos diminuíram linearmente com o aumento da concentração do pó da casca e mesocarpo externo do pequi (Figura 2A e 2C). Na reprodução de $M$. javanica as duas maiores doses, 15 e $30 \mathrm{~g}$ por vaso, reduziram o número de massas de ovos por raiz em 47,8 e $95,8 \%$ em relação à testemunha, respectivamente. (Figura 2B). Não houve efeito das doses sobre o número de $\mathrm{J} 2$ de $M$. javanica $(\mathrm{p}<0,05)$ (dados não apresentados).

A redução do número de galhas, massas de ovos e ovos pode ser explicada provavelmente devido à liberação dos compostos químicos pelo pó de pequi ao serem incorporados ao solo. Tais compostos podem ter diminuído a eclosão de $\mathrm{J} 2$ do nematóide das galhas no solo como constatado, no teste de eclosão in vitro realizado neste estudo, ou o ácido tanínico por ser um composto atrativo a J2 de M. arenaria e incognita, pode ter desorientado os $\mathrm{J} 2$ do nematóide das galhas dificultando a localização das raízes. Desta forma, provavelmente houve redução ou atraso na penetração de J2 com conseqüente redução do número de galhas e massas de ovos (Hewlett et al., 1999). Maistrello et al. (2010) também verificaram a redução da eclosão do nematóide das galhas in vitro e redução do número de ovos de $\mathrm{J} 2$ em tomateiros utilizando taninos de castanheira e atribuíram tal resultado ao efeito nematostático e de desorientação do movimento dos nematoides.

A altura e massa seca da parte aérea de tomateiros inoculados com nematóide das galhas diminuíram com o aumento da concentração do pó da casca e mesocarpo de pequi, pré-estabelecida neste estudo (Figura 3A e 3B ). A redu- 


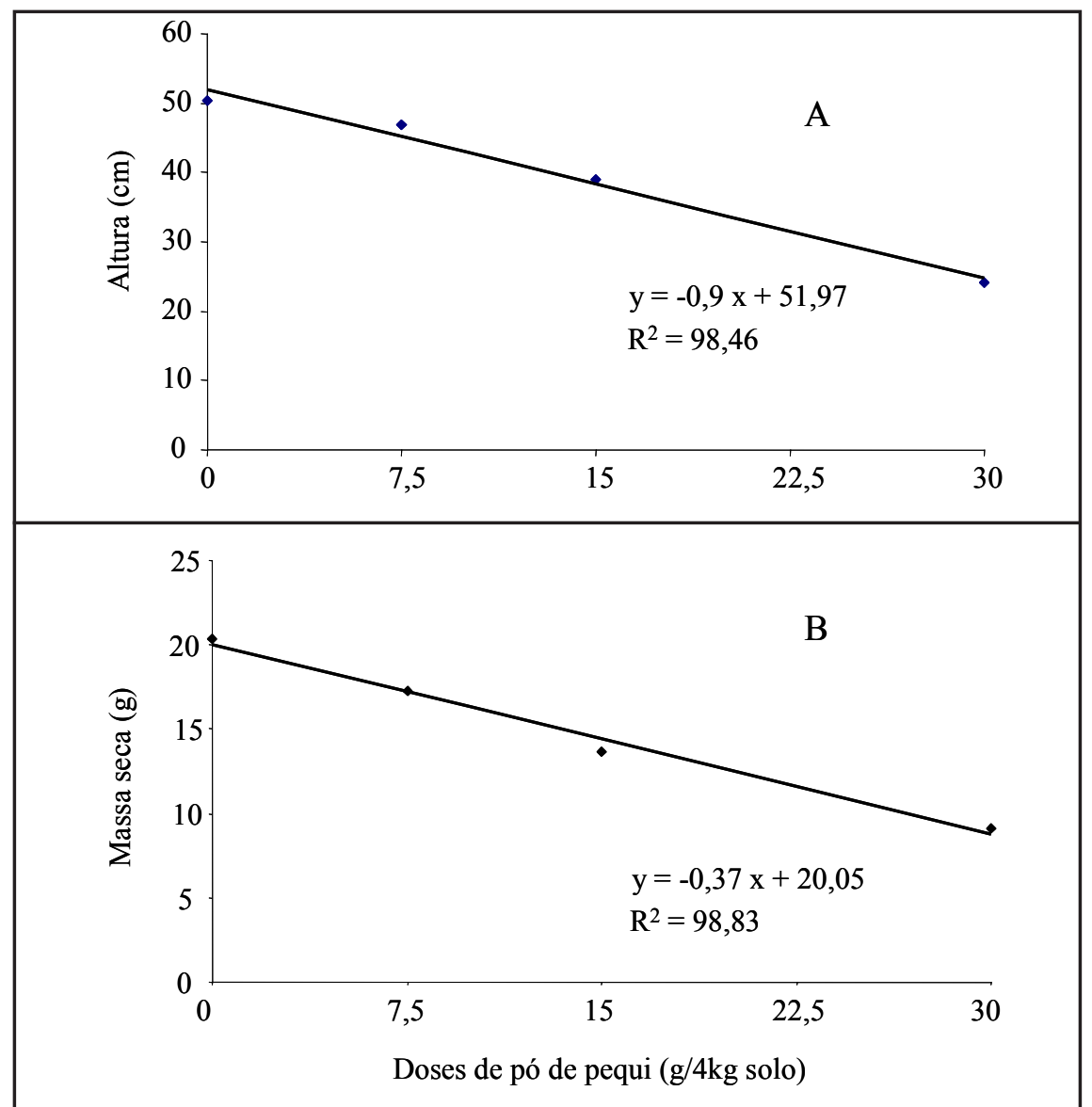

Figura 3. Altura (A) e peso de massa seca da parte aérea (B) de tomateiros inoculados com nematóides das galhas, quarenta e sete dias após a incorporação ao substrato de diferentes doses de pó da casca e mesocarpo do pequi [tomato shoot dry weight (A) and height (B) of tomato plants inoculated with root knot nematode, forty-seven days after the incorporation to the substrate of different doses of pequi powder]. Janaúba, UNIMONTES, 2006.

ção no peso da matéria seca e da altura foi diretamente proporcional às doses do pó e chegou a $55 \%$ e da altura em $52 \%$ com a dose $30 \%$ em relação à testemunha. Fica assim caracterizada a fitotoxicidade pela aplicação das doses testadas.

Compostos aromáticos como taninos encontrados na casca do fruto de pequi, a exemplo dos taninos, reduzem a absorção de vários nutrientes como nitrogênio e fósforo e promovem a interação com enzimas e substâncias promotoras de crescimento, aumentam a absorção de ferro e de outros micronutrientes, e alteram as relações hídricas entre planta e solo (Moreira \& Siqueira, 2002). Indiretamente estes compostos podem influenciar alterações nas características nutricionais da planta no solo e na atividade dos microrganismos no solo (Rice 1984; Rizvi et al. 1992 citados por Borella et al., 2009). Mian \&
Rodriguez-Kábana (1982) verificaram que o ácido tanínico reduziu a população de $M$. arenaria, porém causou severa fitotoxicidade. No presente trabalho o plantio foi efetuado sete dias após a incorporação do pó ao solo. De acordo com Hossain et al. (1992), a eficiência em controlar nematóides-das-galhas com tortas aumenta e o risco de fitotoxidez reduz com o aumento do intervalo de tempo entre a aplicação da torta e o plantio. Jain \& Bhatti (1988) verificaram que o crescimento de tomateiros e o controle de nematoides foi maior quando as folhas de nim (Azadirachta indica) foram incorporadas ao solo seis semanas antes do plantio. A presença destes compostos fenólicos ocorre naturalmente no solo, sendo liberados pelas raízes. Porém a fitotoxicidade destas substâncias é reduzida pela atividade microbiana (Moreira \& Siqueira, 2002). Assim é possível que os efeitos de fitoto- xicidade da casca e mesocarpo de pequi observados nas diferentes doses em relação à testemunha no presente trabalho provavelmente ocorreram devido à ausência de microbiota natural, eliminada pela fumigação do solo. Bhattacharya \& Goswami (1987) verificaram que a torta de Nim foi mais efetiva no controle de nematoides em solo não esterilizado do que em solo esterilizado, possivelmente devido à degradação mais rápida dos tecidos vegetais e liberação de compostos nematotóxicos pela microbiota.

Sugere-se, portanto, que o intervalo entre a aplicação do pó da casca e do mesocarpo do pequi e o plantio da cultura seja superior a sete dias e que novas pesquisas são necessárias para definir esse período anterior ao estabelecimento da cultura evitando, assim, riscos de fitotoxicidade. Conclui-se que o extrato e o pó obtidos da casca e mesocarpo de pequi têm efeito nematicida ao nematóide das galhas, porém causam fitotoxicidade quando misturado ao solo e seguido do plantio até sete dias da sua aplicação ao solo.

\section{AGRADECIMENTOS}

A Fundação de Amparo à Pesquisa do Estado de Minas Gerais (FAPEMIG) pela concessão da bolsa de Incentivo à Pesquisa e ao Desenvolvimento Tecnológico.

\section{REFERÊNCIAS}

ADEGBITE AA; ADESIYAN SO. 2005. Root extracts of plants to control root-knot nematodes on edible soybean. World Journal of Agricultural Science 1: 18-21.

BHATTACHARYA D; GOSWAMI BK. 1987. A study of the comparative efficacy of neem and groundnut oil cakes against rootknot nematodes Meloidogyne incognita influenced by microorganisms on sterilized and unsterelized soil. Indian Journal of Nematology 17: 81-83.

BEZERRA JCB; SILVA IA; FERREIRA HD; FERRI PH; SANTOS SC. 2002. Mollusccidal activity against Biomphalaria glabrata on the Brazilian cerrado medicinal plants. Fitoterapia 73: 428-430.

BONETI JIS; FERRAZ S. 1981. Modificação do método de Hussey \& Barker para extração de ovos de Meloidogyne exigua em raízes de cafeeiro. Fitopatologia Brasileira 6: 553.

BORELLA J; WANDSCHEEN ACD; BONATTI LC; PASTORINI LH. 2009. Efeito alelopático de extratos aquosos de Persea americana Mill. 
sobre Lactuca sativa L. Revista Brasileira de Biociências 7: 260-265.

CHEN SY; DICKSON, DW. 2000. A technique for determining live second-stage juveniles of Heterodera glycines. Journal of Nematology 32: $117-121$

CHITWOOD DJ. 2002. Phtochemical based strategies for nematode control. Annual Rewiew of Phytopathology 40: 221-49.

COSTA SSR; SANTOS MSN; RYAN MF. 2003. Effect of Artemisia vulgaris rhizome extracts on hatching, mortality and plant infectivity of Meloidogyne megadora. Journal of Nematology 35: 437-442.

HARTMAN KM; SASSER JN. 1985. Identification of Meloidogyne species on the basis of differential host test and perineal-pattern morphology. In: BARKER KR; CARTER CC. SASSER JN. (eds). An advanced Treatse on Meloidogyne, Vol. 2, Methodology. Raleigh, NC: North Carolina State, University Graphics, p. 525-543.

HEWLET TE; HEWLET EM; DICKSON DW. 1999. Response of Meloidogyne spp., Heterodera glycines and Radopholus similis to tannic Acid. Journal of. Nematology 29: 737-741.

HOSSAIN MS; ZAHID MI.; MILAN IH. 1992. Effect of decomposition period on the efficacy of two oil cakes for control of root-knot nematode (Meloidogyne incognita). Japanese Journal of Nematology 22: 1-10.

ICBAL Z; SARVAR M; JABBAR A; AHMED S; NISA M; SAJID MS; KHAN MN; MUFTI KA; YASSEN M. 2007. Direct and indirect anthelmintic effects of condensed tannins in sheep. Veterinary Parasitology 144: 125-131.

JAIN RK; BHATTI DS. 1988. Effect of degradation of neem leaves on incidence of root knot nematode in tomato transplants. Indian Journal of Nematology 8: 19-24.

JENKINS WR. 1964. A rapid centrifugal-flotation technique for separating nematodes from soil. Plant Disease Reporter 48: 692.

JESSE YA; SULE H; PHILIP CB. 2006. Doruwa (Parkia biglobosa) fruit husk and hyptis (Hyptis spicigera) leaves for controlling rootknot nematodes (Meloidogyne incognita) in tomato (Lycopersicon esculentum Mill CV).
Journal of Tropical Agriculture 44: 83-85.

LOPES E; FERRAZ S; GRASSI LF; FERREIRA PA. 2008. Controle de Meloidogyne javanica com diferentes quantidades de torta de nim (Azadirachta indica). Revista Trópica Ciências Agrárias e Biológicas 2: 17-21.

MARQUES CSM; CARDOSO MG; SOUZA PE; GAVILANES ML; SOUZAA; PEREIRANE; NEGRÃO IO. 2002. Efeito fungitóxico dos extratos de Caryocar brasiliense Camb. sobre os fungos Botrytis cinerea, Colletotrichum truncatum e Fusarium oxysporum. Ciência e Agrotecnologia, Edição especial: 1410-1419.

MAISTRELLO L; VACCARI G; SASANELLI N. 2010. Effect of chestnut tannins on the root-knot nematode Meloidogyne javanica. Helminthologica 47: 48-57.

MIAN IH; RODRIGUEZ-KÁBANA R. 1982. Organic amendments with tannin and phenolic contents for control of Meloidogyne arenaria in infested soil. Nematropica 12: 221-234.

MOREIRA FMSM; SIQUEIRA JO. 2002. Microbiologia e bioquímica do solo. Lavras: UFLA. $629 \mathrm{p}$.

NAZARENO GG; RESENDE AM; PEIXOTO JR. 2010. Efeito da matéria orgânica na multiplicação de nematoide das galhas em alface sob cultivo protegido. Bioscience 6: 525-530.

OLABIYI TI. 2004. Assessment of the nematicidal properties of extracts from Tagetes erecta, Ocimum gratissimu, hyptis suaveolous and Crotalaria retusa. Ilorin, Nigeria: University of Ilorin. 177p. (Tese).

OLABIYI TI; AKANBI WB; ADEPOJU IO. 2007. Control of certain nematode pests with different organic manure on cowpea. American-Eurasian Journal of Agricultural and Environmental Science 2: 523-527.

OLABIYI TI; OYEDUMADE EEA; IBIKUNLE GL; OJO OA, ADESINA GO; ADELASOYE KA; OGUNNIRAN TA. 2008. Chemical composition and bio-nematicidal potencial of some weed extracts on Meloidogyne incognita under laboratory conditions. Plant Sciences Research 1: 30-35.

OYEDUMADE EEA; OLABIYI TI. 2005. Effect of carbofuran and aqueous extracts of the leaves and root of basil (Ocimum gratissimum L.) in the control of a root nematode, Meloidogyne incognita on Celosia argentea (L). Journal of Agricultural Research \& Development 4: 228-235.

PEGORARO RF; SILVA IR; NOVAIS RFM; SÁ E; ALVAREZ VH; NOVAIS F; MOREIRA FF; SMYTH TJ. 2005. Diffusive flux of cationic micronutrients in two oxisols as affected by low molecular weight organic acids and cover crop residue. Journal of Plant Nutrition and Soil Science 168: 334-341.

PEREZ E. 2004. Diagnose fitoquímica dos frutos de Caryocar brasiliense Camb., Caryocaraceae. Curitiba: UFPR. 113p. (Dissertação mestrado).

RAMOS SJ; ALVES DS; FERNANDES LA; COSTA CA. 2009. Ciência Rural 39: 15721576.

RIBEIRO RF. 2000. Pequi: o rei do cerrado. Belo Horizonte: Rede Cerrado, 62p.

SALGADO SML; CAMPOS VP. 2003. Eclosão e mortalidade de Meloidogyne exigua em extratos e em produtos naturais. Fitopatologia Brasileira 28: 166-170.

SANTOS A. Usos e impactos ambientais causados pela manipueira na microregião sudoeste da Bahia-Brasil. In: LUZON JL; CARDIM M. (coord). Problemas sociales y regionales em América Latina: estúdio de casos. Barcelona: Universitat de Barcelona, 2009. p. 11-25.

SCALBERT A. 1991. Antimicrobial properties of tannins. Phytochemistry 30: 3875-3883.

SHANER G; FINNEY RE. 1977. The effect of nitrogen fertilization on the expression of slow-mildewing resistance in Knox wheat. Phytopathology 67: 1051-1056.

TAYLOR AL; SASSER JN. 1978. Biology, identification and control of root-knot nematodes (Meloidogyne species). North Caroline: International Meloidogyne Project. $111 \mathrm{p}$.

VIEIRA RF; MARTINS MVM. 2000. Recursos genéticos de plantas medicinais do cerrado: uma compilação de dados. Revista Brasileira de Plantas medicinais. 3: 13-36.

ZUCHI J; BEVILAQUA GAP; GALHO A; MARQUES RLE, SILVA STA. 2007. Efeito de torta de mamona sobre componentes de rendimento de trigo. Revista Brasileira de Agroecologia 2: 1080-1083. 